\title{
Research of Electrocardiographic and Echocardiographic Abnormalities in Rheumatoid Arthritis without Clinical Cardiovascular Events
}

Mouhamadou Nazirou Dodo-Siddo ${ }^{*}$, Mouhamadou Bamba Ndiaye ${ }^{1}$, Malick Bodian', Simon Antoine Sarr ${ }^{1}$, Souhaibou Ndongo², Adama Kane $^{1}$, Alassane Mbaye ${ }^{3}$, Tahirou lliassou ${ }^{1}$, Habibou Harouna ${ }^{1}$, Maboury Diao', Moustapha SARR ${ }^{1}$, Abdoul Kane ${ }^{3}$, Serigne Abdou BA ${ }^{1}$ and Thérèse Moreira Diop ${ }^{2}$

${ }^{1}$ Service of Cardiology, Hospital Aristide Le Dantec Dakar, Senegal

${ }^{2}$ Internal Medicine, Hospital Aristide Le Dantec Dakar, Senegal

${ }^{3}$ Service of Cardiology, General Hospital of Grand Yoff, Senegal

\begin{abstract}
Introduction: IT has been known for many years that the heart may be involved in rheumatoid arthritis. The aim of this study is to investigate the electrocardiographic and echocardiographic abnormalities in a population of Senegalese patients with rheumatoid arthritis without clinical cardiovascular disease.

Patients and method: Seventy three consecutive patients between the age of 18 and 75 years admitted to the internal medicine department of University Hospital Center Aristide Le Dantec in Dakar, Senegal, with a diagnosis of rheumatoid arthritis without clinically evident cardiovascular disease. Each patient had a cardiological assessment which included a history and examination with ECG, echocardiography standard. We conducted laboratory tests (CRP, fibrinogen, ESR, Rheumatoid factors: Latex and Waaler Rose, Anti-CCP, antinuclear factors and anti-ENA antibodies). Data were analyzed using a descriptive study of the different variables with the calculation of proportions for categorical variables, and the positional parameters and dispersion for quantitative variables.

Results: Sixty eight female and five patients with rheumatoid arthritis without obvious cardiac events meet the criteria of definition of the ACR 1987 were studied. The mean age was $44.17 \pm 14.43$ years with extremes of 18 and 75 years. The mean duration of RA was $5.93 \pm 4.78$ years. The concept of family inflammatory arthritis was reported in $35.60 \%$ of cases and almost one in six patients had at least a factor of cardiovascular risk $(16.96 \%)$.

Electrocardiographic findings were dominated by a left axis deviation in $16.44 \%$ of patients and 34 patients $(46.57 \%)$ had left ventricular hypertrophy. Myocardial hyperexcitability was present in 8 patients $(11.19 \%)$, including 6 premature ventricular found in patients with active RA. Twenty-six patients $(35.61 \%)$ showed signs consistent with ischemia and / or myocardial injury. The echocardiography abnormalities were dominated by diastolic LV dysfunction $(42.46 \%)$, increased left ventricular mass in $35.61 \%$. Valvular leaks grades variables been highlighted regarding all orifices but rarely significant.
\end{abstract}

Conclusion: Electrocardiogram and echocardiogram are a sensitive and reliable diagnostic aid for the detection of cardiac lesions in rheumatoid arthritis without clinical cardiovascular events.

Keywords: Rheumatoid arthritis; Electrocardiographic and echocardiographic; Clinical cardiovascular events

\section{Introduction}

As a connective tissue disease, rheumatoid arthritis (RA) may affect various organs. In it, a greater number of changes in the cardiac system have been noted after death. Several large epidemiological studies found more excess cardiovascular mortality in RA patients than in controls [1-4]. The mechanisms that explain the rise in cardiovascular morbidity and mortality have not yet been elucidated. However, it seems that traditional cardiovascular risk factors contribute but elements specific to RA, including the existence of an inflammation of the endothelium exposed to accelerated atherosclerosis [5].

Several studies have reported a higher risk of cardiovascular death and cardiovascular complications as compared with the general population [6,7]. The leading causes of cardiovascular death in RA are Ischaemic heart disease [8] and heart failure as a consequence of either systolic or diastolic dysfunction $[9,10]$. Disturbances of diastolic function precede systolic heart failure and, although clinically silent, represent the earliest sign of cardiac involvement [11]. Thus; screening for cardiovascular abnormalities is of paramount importance and must be part of logic of secondary prevention. This screening is based mainly on electrocardiography and echocardiography which are non-invasive relatively acceptable cost. The aim of our study was to investigate cardiovascular abnormalities in patients with rheumatoid arthritis without clinical cardiovascular events.

\section{Patients and Methods}

Descriptive cross-sectional study, prospectively which included 73 consecutive outpatients with rheumatoid arthritis (68 females, 5 males) in the internal medicine department of Hospitalo-University Centre Aristide Le Dantec in Dakar, Senegal, classified according to the criteria of the American College of Rheumatology 1987 [12] and free of any evidence of cardiovascular disease. Study subjects were recruited from

*Corresponding author: Mouhamadou Nazirou Doddo Siddo, cardiologist, Service of Cardiology, Hospital Aristide Le Dantec Dakar, Senegal, Tel: 0022796778686; E-mail: nazdodo@yahoo.fr

Received April 28, 2015; Accepted May 25, 2015; Published June 02, 2015

Citation: Dodo-Siddo MN, Ndiaye MB, Bodian M, Sarr SA, Ndongo S, e tal (2015) Research of Electrocardiographic and Echocardiographic Abnormalities in Rheumatoid Arthritis without Clinical Cardiovascular Events. J Arthritis 4: 154 doi:10.4172/2167-7921.1000154

Copyright: (c) 2015 Dodo-Siddo MN, et al. This is an open-access article distributed under the terms of the Creative Commons Attribution License, which permits unrestricted use, distribution, and reproduction in any medium, provided the original author and source are credited. 
April 2009 to May 2010 both sexes aged at least 18 years old. Patients were included after an informed consent was obtained.

All subjects underwent complete physical examination and were questioned about possible cardiovascular events in the past, major cardiovascular disease risk factors (diabetes, dyslipidaemia, hypertension and smoking) as recommended by the Afssaps [13]

For each patient, the following data were recorded: age, sex, disease duration, clinical manifestations, successive treatments (especially steroids), the disease activity scores (DAS 28), Exclusion criteria were as follows :all patients with known cardiac disease outside the blood pressure, symptoms suggestive of cardiovascular disease or treatment referred cardiology (excluding high blood pressure). Routine haematological and biochemical measurements were performed, including: erythrocyte sedimentation rate (ESR), C-reactive protein (CRP), rheumatoid factor (RF) (Latex and Waaler Rose), antinuclear antibodies (ANA), anti-dsDNA antibodies and anti-peptide citric citrullinated (anti-CCP). Patients selected for the study had had a resting ECG (standard, 12-lead). All echocardiograms were performed by single experienced and registered diagnostic cardiac sonographers. We performed echocardiography through System Five Performance trademarks of devices equipped with a $2 \mathrm{MHz}$ transducer and ViVid E7 equipped with a $3 \mathrm{MHz}$ transducer to perform a movement examination time mode (TM), two-dimensional, Doppler direct, pulse, color and tissue. The preferred structures were pericardium, endocardium and valves and myocardium (appearance and kinetics). The parameters studied were the transthoracic echocardiography anteroposterior diameter of the left atrium, the surface of the left atrium, the diameters of the left ventricle end diastolic diameter and its walls (LVEDd), systolic (LVESd), posterior wall (PW) and interventricular septum (IVS) in diastole and systole from a cup TM (time motion). Left ventricular mass (LVM) was obtained using the formula: LVM = $0.8\left[1.04(\text { LVEDd + IVS + PW })^{3}-\right.$ LVEDd $\left.^{3}\right]-0.6 \mathrm{~g}$ according to the convention of the American Society of Echocardiography (ASE) [14]. Ejection fraction was determined by the method of Teichholz's. We also measured the peak speed and full time $\mathrm{E}$ wave velocity, peak speed and full-time speed of the wave A, the deceleration time of the $\mathrm{E}$ wave (TDE) and the isovolumetric relaxation time (IVRT). Filling pressures of the left ventricle were measured from the formula: $\mathrm{Em} / \mathrm{Ea}$ (Ea is measured at the side wall). Pulmonary artery pressure was assessed by Doppler assessment of the flow of tricuspid regurgitation and/or pulmonary failure.

\section{Data Processing}

The analysis plan was made according to a descriptive study of the different variables with the calculation of proportions for categorical variables, and the position and dispersion parameters for quantitative variables using the SPSS 17 program of 73 patients. The study population is secondarily divided into two subgroups according to the presence or absence of diastolic dysfunction in echocardiography and according the sex. A Mann Whitney test was then used for the comparison of standard echocardiography parameters between the two groups in order to highlight the parameters significantly associated with the presence of diastolic dysfunction in the study population. Any value of $\mathrm{p}<0.05$ was considered significant.

\section{Results}

The 73 patients with rheumatoid arthritis ranged in age from 18 to 75 years; mean age at diagnosis was $44.17 \pm 14.43$ years and mean duration of disease was $5,93 \pm 4,78$ years. Baseline characteristics of the study population are summarized in Table 1. Main electrocardiographic abnormalities are reported in Table 2. There was no significant difference between the two groups male and female with regard to heart rate, PR interval, QRS duration and QT interval.

There is a significant number of left ventricular hypertrophy (46.57\%) and left atrial (32.90\%). Analysis, it appears that the existence of these anomalies is correlated with age. In bivariate analysis, left ventricular hypertrophy was associated with increased left ventricular mass in 21 patients $(28.76 \%$ ). Left axis deviation was found in $16.44 \%$ of patients. The hyper excitability myocardial was present in 8 patients $(11.19 \%)$ of which $6(8.45 \%)$ premature Ventricular found in patients with active RA. Twenty-six patients showed signs consistent with ischemia and / or myocardial injury a rate of $35.61 \%$.

Conventional echocardiographic and Doppler parameters are summarized in Table 3. The abnormalities found in Doppler echocardiography were dominated by a diastolic LV dysfunction $(42.46 \%)$, an increase in left ventricular mass in $35.61 \%$. Valvular leak grades variables were identified affecting all ports but rarely significant as $21.05 \%$ of cases of mild pulmonary hypertension. The different echocardiographic abnormalities are listed in Table 4. Comparative echocardiographic parameters between patients with RA according to the type and according to the presence or absence of diastolic dysfunction respectively in Tables 5 and 6 . It appears that the existence of diastolic dysfunction in our patients is correlated with the disease activity in rheumatoid factor positivity and age of patient. Inflammation might be associated with the observed cardiac findings in these patients.

\section{Discussion}

To date, several studies have highlighted the importance of cardiovascular risk [15] showing interest in electrocardiogram [16] and echocardiography [17] in patients with rheumatoid arthritis without

\begin{tabular}{|c|c|c|c|c|}
\hline $\begin{array}{c}\text { Demographic } \\
\text { characteristics, } \\
\text { cardiovascular risk } \\
\text { factors }\end{array}$ & $\begin{array}{c}\text { Women } \\
n=65\end{array}$ & Men $\mathrm{n}=\mathbf{8}$ & $\begin{array}{c}\text { General } \\
\text { population } \\
n=73\end{array}$ & $\mathbf{p}$ \\
\hline Age (years) : mean $\pm S D$ & $48.11 \pm 10.58$ & $\begin{array}{c}41.91 \pm \\
13,45\end{array}$ & $44.17 \pm 14.43$ & $<0.05$ \\
\hline Sex ratio : $M / F$ & & & 0.12 & \\
\hline Hypertension & 12 & 3 & 15 & $<0.001$ \\
\hline Diabetis Milletis & 4 & 0 & 4 & $<0.001$ \\
\hline Dyslipidémia & 2 & 0 & 2 & \\
\hline Current smoker & 0 & 5 & 5 & $<0.001$ \\
\hline \multicolumn{5}{|c|}{ Characteristics of rheumatoid arthritis } \\
\hline $\begin{array}{c}\text { Mean disease duration } \\
\text { (year) } \pm \text { SD }\end{array}$ & $5.85 \pm 4.81$ & $5.01 \pm 1.14$ & $5.93 \pm 4.78$ & NS \\
\hline Nodule $(\%)$ & 1 & 2 & $3(4.11 \%)$ & NS \\
\hline DAS 28 (mean score ) & 5.40 & 5.78 & 5.50 & NS \\
\hline $\mathrm{RF}(\mathrm{Ul} / \mathrm{ml}): \%$ (mean) & 78.65 & 75.22 & $76.4(88.10)$ & NS \\
\hline Ac anti-CCP(Ul/ml): (mean) & 51.45 & 53.98 & $52.05(205.95)$ & NS \\
\hline PRC (mg/l) : moyenne & 42.28 & 40.65 & 41.32 & NS \\
\hline ESR (mm/first hour) : mean & $36.34 \pm 12$ & $35.54 \pm 18$ & $38.96 \pm 23$ & NS \\
\hline $\begin{array}{c}\text { Family history of } \\
\text { rheumatoid arthritis: } \mathrm{n}(\%)\end{array}$ & 5 & 21 & $26(355.60 \%)$ & $<0.0001$ \\
\hline
\end{tabular}

DAS: Disease Activity Score, CRP C-reactive protein

Table 1: Baseline characteristics of study population. 
Citation: Dodo-Siddo MN, Ndiaye MB, Bodian M, Sarr SA, Ndongo S, e tal. (2015) Research of Electrocardiographic and Echocardiographic Abnormalities in Rheumatoid Arthritis without Clinical Cardiovascular Events. J Arthritis 4: 154. doi:10.4172/2167-7921.1000154

Page 3 of 6

\begin{tabular}{|c|c|c|c|c|}
\hline Electrocardiogram parameters & Women $n=65$ & Men $n=5$ & General population $n=75$ & $\mathrm{p}$ \\
\hline Average heart rate \pm SD & $83.54 \pm 17.11$ & $78.87 \pm 14.52$ & $82.80 \pm 16.22$ & NS \\
\hline PR interval (ms) mean $\pm \mathrm{SD}$ & $149.51 \pm 20.12$ & $153.25 \pm 22.57$ & $150.50 \pm 20.82$ & NS \\
\hline QRS duration (ms) & $85.11 \pm 19.00$ & $83.15 \pm 15.23$ & $83.00 \pm 15.00$ & NS \\
\hline QT Interval (ms) & $40.99 \pm 4.62$ & $38.65 \pm 3.27$ & $40.32 \pm 3.66$ & NS \\
\hline Anomaly of heart's axis & $12(16.43 \%)$ & $3(4.11 \%)$ & $15(20.54 \%)$ & $<0.001$ \\
\hline Presence of atrial premature beat & $2(2.74 \%)$ & 0 & $2(2.74 \%)$ & \\
\hline Presence of ventricular premature & $5(6.84 \%)$ & $1(1.36 \%)$ & $6(8.45 \%)$ & $<0.05$ \\
\hline \multicolumn{5}{|l|}{ AVB: Atrioventricular block } \\
\hline $\mathrm{I}$ & $2(2.74 \%)$ & 0 & $2(2.74 \%)$ & \\
\hline II & 0 & 0 & 0 & \\
\hline III & 0 & 0 & 0 & \\
\hline CRBBB ou IRBBB & $2(2.75 \%)$ & 0 & $2(2.75 \%)$ & \\
\hline CRBBB ou IRBBB & $3(4.11 \%)$ & 0 & $3(4.11 \%)$ & \\
\hline myocardic ischemia * & $25(34.24 \%)$ & $2(2.75 \%)$ & $27(36.98 \%)$ & $<0.0001$ \\
\hline
\end{tabular}

Table 2: Main electrocardiographic abnormalities.

AVB: atrioventricular block type I, II, III; CLBBB: Complete left bundle branch block.

ILBBB: Incomplete left bundle branch block; CRBBB: Complete right bundle branch block; IRBBB: Incomplete right bundle branch block. *signs compatible with myocardial ischemia (presence of a $Q$ wave necrosis, T wave changes or ST segment)

\begin{tabular}{|c|c|c|c|c|c|}
\hline Echocardiography Parameters & Males & Womens & General Population $(n=73)$ & normal value & $\mathbf{p}$ \\
\hline LVEDd $(\mathrm{mm})$ & $46.88 \pm 3.15$ & $44.51 \pm 5.45$ & $45.79 \pm 4.48$ & $45-56$ & NS \\
\hline LVESd (mm) & $30.20 \pm 5.48$ & $28.35 \pm 4.21$ & $28.65 \pm 4.48$ & $25-35$ & NS \\
\hline IVS (mm) & $9.20 \pm 1.20$ & $7.33 \pm 1.24$ & $7.48 \pm 1.69$ & $7-11$ & NS \\
\hline LVPW (mm) & $8.72 \pm 1.30$ & $7.48 \pm 1.23$ & $7.66 \pm 1.25$ & $7-11$ & NS \\
\hline LVM (penn) g & $125.10 \pm 38.8$ & $105.20 \pm 41.00$ & $107.79 \pm 29.32$ & $\begin{array}{l}<110 \text { female } \\
<135 \text { male }\end{array}$ & $<0.01$ \\
\hline LVEDV(Teilcholz)ml & $103.25 \pm 19.87$ & $95.37 \pm 29.52$ & $98.10 \pm 21.99$ & & $<0.05$ \\
\hline LVESV (Teicholtz) ml & $37.22 \pm 10.15$ & $31.12 \pm 11.53$ & $32.02 \pm 11.31$ & & $<0.05$ \\
\hline Aortic root (mm) & $29.87 \pm 3.54$ & $28.14 \pm 1.61$ & $29.00 \pm 2.47$ & $16-35$ & NS \\
\hline LAD (mm) & $33.15 \pm 4.23$ & $31.08 \pm 5.01$ & $32.02 \pm 4.32$ & $22-40$ & NS \\
\hline LA/Aortic & $1.01 \pm 0.33$ & $0.98 \pm 0.58$ & $1.08 \pm 0.46$ & $0.90-1$ & NS \\
\hline $\mathrm{RV}$ diastolic (mm) & $22.14 \pm 1.53$ & $20.24 \pm 1.14$ & $20.38 \pm 0.08$ & 27 & NS \\
\hline $\mathrm{EF}(\%)$ & $65.47 \pm 5.88$ & $62.85 \pm 4.44$ & $67.04 \pm 4.66$ & $55-75$ & NS \\
\hline FS (\%) & $38.65 \pm 4.29$ & $36.41 \pm 5.98$ & $37.59 \pm 5.48$ & $28-42$ & NS \\
\hline TAPSE (mm) & $22.45 \pm 4.11$ & $21.58 \pm 24$ & $22.16 \pm 6.36$ & 17 & NS \\
\hline MAPSE (mm) & $14.41 \pm 2.17$ & $13.76 \pm 1.87$ & $13.50 \pm 1.80$ & 11 & NS \\
\hline IVC (mm) & $14.87 \pm 5,12$ & $13.32 \pm 6.25$ & $13.49 \pm 6.05$ & 15 & NS \\
\hline
\end{tabular}

LVEDd: Left ventricular end-diastolic dimension; LVESd : Left ventricular end-systolic dimension; IVS: Interventricular septum; LVPW: Left ventricular posterior wall; mm : millimeter; LVM: Left ventricular mass; VTDVG: volume télédiastolique du ventricule gauche; VTSVG :volume télésystolique du ventricule gauche; mL : millilitre; LA : Left atrium; RV : right ventricular; EF : Ejection fraction; FR : fractional shortening; TAPSE : excursion systolique du plan de l'anneau tricuspide; MAPSE : excursion systolique du plan de l'anneau mitral; $\mathrm{VCl}$ : veine cave inférieure.

Table 3: Conventional echocardiography and Doppler parameters.

\begin{tabular}{|c|c|c|c|c|c|}
\hline $\begin{array}{l}\text { Echocardiography } \\
\text { Parameters }\end{array}$ & Number & Males & Females & Percentage (\%) & p \\
\hline LVEDd>56mm & 1 & 0 & 1 & 1.36 & \\
\hline LAD>40mm & 5 & 0 & 5 & 6.85 & $<0.05$ \\
\hline $\mathrm{SLA}>20 \mathrm{~cm}^{2}$ & 3 & 0 & 3 & 4.11 & \\
\hline $\begin{array}{l}\text { LVMI }>115 \mathrm{~g} / \mathrm{m}^{2} \text { man } \\
\begin{array}{l}\text { LVMI }>105 \mathrm{~g} / \mathrm{m}^{2} \\
\text { woman }\end{array}\end{array}$ & & 2 & 24 & & $<0.0001$ \\
\hline Increased LVIM & 26 & 1 & 25 & 35.61 & $<0.0001$ \\
\hline RVEDd>27mm & 5 & 3 & 2 & 6.85 & NS \\
\hline Anevrysm of IAS & 2 & 0 & 2 & 2.74 & \\
\hline
\end{tabular}

LVDEDd: Left Ventricular End Diastolic Dimension; mm: millimeter; LAD: Left Atrium Dimension; SLA: Surface of the Left Atrium; LVMI: Left Ventricular Mass Index; RVEDd : Right Ventricular End Diastolic Dimension; NS : No Significant; IA S: Septum Interatrial Septum

Table 4: Comparative distribution of echocardiography abnormalities according the sex. cardiovascular events. To our knowledge there is no study in Africa that sought both electrical and echocardiographic abnormalities in RA in asymptomatic patients.

Analysis was performed to address the concern of higher prevalence of some traditional cardiovascular risk factors. The study highlights the overall prevalence was $16.33 \%$, and especially hypertension $20,55 \%$. Hypertension was known in $60 \%$ and unknown in $40 \%$ and suggests the importance of screening and systematic support for it in the PR. The concept of family inflammatory rheumatism was reported in $35.60 \%$ of cases. Our results are in agreement with those of several studies [18,19] who pointed out that the risk of occurrence of RA is two to three times higher in the offspring of a patient with the disease although it however, is not a genetically transmitted disease. In Senegal, a case of PR in four part of an inflammatory arthritis family [20].

Electrocardiographic abnormalities during the observed RA are 
Citation: Dodo-Siddo MN, Ndiaye MB, Bodian M, Sarr SA, Ndongo S, e tal. (2015) Research of Electrocardiographic and Echocardiographic Abnormalities in Rheumatoid Arthritis without Clinical Cardiovascular Events. J Arthritis 4: 154. doi:10.4172/2167-7921.1000154

\begin{tabular}{|c|c|c|c|c|}
\hline $\begin{array}{c}\text { Diastolic dysfunction } \\
\begin{array}{c}\text { Diastolic dysfunction (classification } \\
\text { de Redfield [16]) }\end{array}\end{array}$ & Males & Females & Total & p \\
\hline -Normal : & 5 & 33 & $38(52.05 \%)$ & $<0.0001$ \\
\hline $\begin{array}{c}0.75<\text { E/A1.5< and E/ } \\
\text { Ea<10 }\end{array}$ & & & & \\
\hline DT>140ms & & & & \\
\hline Mild diastolic dysfunction: & 1 & 12 & $13(17.81 \%)$ & $<0.001$ \\
\hline E/A=0.75 and E/Ea<10 & & & & \\
\hline - Moderate diastolic dysfunction: & 2 & 15 & $17(23.29 \%)$ & $<0.001$ \\
\hline $0.75<$ E/A<1.5 and E/Ea>10 & & & & \\
\hline DT>140 ms & & & & \\
\hline- Severe diastolic dysfunction: & 0 & 5 & $5(6.85 \%)$ & $<0.01$ \\
\hline E/A>1.5 and E/Ea>10 & & & & \\
\hline DT<140 ms & & & & \\
\hline Diastolic dysfunction (Redfield): & & & & \\
\hline yes & 1 & 34 & $35(47.95 \%)$ & $<0.0001$ \\
\hline no & 4 & 34 & $38(52.05 \%)$ & $<0.001$ \\
\hline $\begin{array}{c}\text { Conventionnel diastolic } \\
\text { dysfunction: }\end{array}$ & & & & \\
\hline$-\quad$ E/A<1 & 1 & 30 & $31(42.46 \%)$ & $<0.001$ \\
\hline$-\quad$ E/A>1 & 4 & 38 & $42(57.54 \%)$ & $<0.0001$ \\
\hline Tissue Doppler imaging: & & & & \\
\hline$-\quad$ E/Ea<10 & 3 & 46 & $49(67.23 \%)$ & $<0.0001$ \\
\hline$-\quad$ E/Ea 10-15 & 2 & 21 & $23(31.50 \%)$ & $<0.0001$ \\
\hline$-\quad$ E/Ea>15 & 0 & 1 & $1(1.37 \%)$ & \\
\hline
\end{tabular}

found depolarization, were those of the negative $\mathrm{T}$ wave $(35.61 \%)$ In the French study on the value of routine electrocardiography in the detection of cardiac involvement in rheumatoid arthritis, abnormalities most frequently found repolarization were also negative $\mathrm{T}$ waves (21\%) [16]. Echocardiographic anomalies in our study are diverse. The prevalence of pericardial disease is $6.86 \%$. This is a small pericardial effusion abundance without clinical manifestations. This rate is much lower than that found in most studies reported initially ranging on average from 30 to $50 \%$ [24,25,26]. The singlecenter nature of the study and management including background processing administration, could help to explain the low number of pericardial disease encountered. However, iatrogenic pericarditis secondary to taking methotrexate for maintenance treatment of RA, has also been reported [27] and $61.64 \%$ of the patients in our study were under Methotrexate. Échocargraphiques systematic studies in RA in the US [28] found themselves $30 \%$ predominant valvular remodeling on mitral valves followed by aortic valves. The prevalence of increased left ventricular mass in our study population was $35.61 \%$. In bivariate analysis, we found that left ventricular hypertrophy was associated with increased left ventricular mass in 21 patients $(28.76 \%)$ Rebecca et al. [29] in their series, found themselves a correlation between rheumatoid arthritis and increased LV mass. This could be explained by the role of chronic inflammation in myocardial mass. The prevalence of diastolic dysfunction as classified by Redfield et al. [30], was $47.95 \%$. This result is identical to that of Abdul Muizz et al. [31] who found a prevalence of $47.20 \%$ and less than Udayakumar et al. [24] with a prevalence of $42.20 \%$. The average diastolic dysfunction prevalence was $17.81 \%$, moderate diastolic dysfunction was $23.29 \%$ and $6.85 \%$ severe, while Abdul Muizz et al. [23], were respectively $1.90 \%$,

different. We basically met with left ventricular hypertrophy (46.57\%), where nearly one in two patients presented this anomaly. The fact is that just as the left atrial hypertrophy, the left ventricular hypertrophy were observed especially after the after the age of 50 years. The explanation could be related to the natural history of arthritis which is considered our day as a cardiovascular risk factor [21] but mainly from the combination of other comorbidities including diabetes, hypertension and age [22]. The disorder association of the minor conduction (1st degree AV block) is rarely encountered in our study, as pointed out by Goulenok [16]. Abnormalities PQ segment (offset) found in 10 patients $(13.70 \%)$ could be related to the inflammation of the pericardium induced by RA. Myocardial hyperexcitability is found in our patients in the form of premature beat is related to disease activity imposed by inflammation. Wislowska [23] showed that the cardiovascular risk is all the more important that the inflammatory balance is disturbed. Similarly Seferovic PM [24], in a study of arrhythmias and conduction disorders in rheumatic autoimmune diseases origins, noted that the presence of these abnormalities were more frequent in patients with active RA. Abnormalities intraventricular conduction was $6.86 \%$. Villeco [25], in his series, found a different result with a high frequency of branch block particular rights (35\%). In our study a BBD association and rheumatoid nodule was more met as described by Lutalo in Zimbabwe [26]. This type of anomaly is a common phenomenon in rheumatoid arthritis and may be due to infiltration of the conduction tissue induced by the inflammatory process. The average length of measured and calculated QT intervals were respectively 388 and $403 \pm$ $27 \mathrm{~ms} \pm 36 \mathrm{~ms}$. Goulenok et al. [16] in their series, found themselves an average duration of the QT interval calculated from $367 \pm 26 \mathrm{~ms}$, lower than in our study. The calculated QT interval was normal in $71.23 \%$ of cases in our study. The prevalence of QTc interval was $28.77 \%$. This could among others be explained by the effect of antimalarials on the duration of the QT interval. Abnormalities most frequently

\begin{tabular}{|c|c|c|c|}
\hline Parameters & $\begin{array}{l}\text { Patients with } \\
\text { diastolic } \\
\text { dysfunction } \\
(\mathrm{n}=35)\end{array}$ & $\begin{array}{c}\text { Patients without } \\
\text { Diastolic } \\
\text { dysfunction }(n=38)\end{array}$ & $P$-value \\
\hline LVEDd (mm) & $44.65 \pm 3.75$ & $45.09 \pm 3.48$ & NS \\
\hline LVEDd (mm) & $28.43 \pm 4.95$ & $27.85 \pm 4.35$ & NS \\
\hline IVS (mm) & $7.55 \pm 1.78$ & $7.98 \pm 1.59$ & NS \\
\hline LVPW (mm) & $7.88 \pm 1.38$ & $7,56 \pm 1,35$ & NS \\
\hline MVG(penn)g & $108.53 \pm 29.58$ & $106.32 \pm 28.09$ & NS \\
\hline Aortic $\operatorname{root}(\mathrm{mm})$ & $29.11 \pm 2.47$ & $29.42 \pm 2.08$ & NS \\
\hline LA $(\mathrm{mm})$ & $31.88 \pm 3.65$ & $32.54 \pm 4.32$ & NS \\
\hline LA/Aortic & $1.16 \pm 0.46$ & $1.01 \pm 0.26$ & NS \\
\hline RVEDd & $22.04 \pm 1.45$ & $19.88 \pm 3.48$ & $<0.05$ \\
\hline $\mathrm{EF}(\%)$ & $68.78 \pm 5.79$ & $66.04 \pm 6.36$ & NS \\
\hline FS & $37.05 \pm 6.18$ & $38.56 \pm 5.58$ & NS \\
\hline TAPSE & $21.48 \pm 4.75$ & $22.01 \pm 5.36$ & NS \\
\hline MAPSE & $11.95 \pm 2.43$ & $14.02 \pm 1.30$ & $<0 ? 05$ \\
\hline$E$ & $0.68 \pm 0.48$ & $0.73 \pm 0.27$ & 0,01 \\
\hline A & $0.78 \pm 0.42$ & $0.67 \pm 0.21$ & NS \\
\hline$E / A$ & $0.87 \pm 0.38$ & $1.38 \pm 0.16$ & $<0,001$ \\
\hline TD & $215.41 \pm 58.54$ & $206.04 \pm 50.55$ & $<0,05$ \\
\hline TRIV & $75.88 \pm 12.21$ & $101.02 \pm 18.23$ & $<0.001$ \\
\hline \multicolumn{2}{|r|}{$0.08 \pm 0.12$} & \multirow{2}{*}{$\begin{array}{l}0.10 \pm 0.02 \\
9.02 \pm 1.11\end{array}$} & $<0.05$ \\
\hline E/Ea & $10.84 \pm 1.41$ & & NS \\
\hline
\end{tabular}

NS : No Significaant ; LVEDd : Left Ventricle End Diastolic Dimension; mm millimeter; LVEDd : Left Ventricle End Diastolic Dimension; IVS: Interventricular Septum; LVPW: Left Ventricular Posterior Wall ; LVM :Left Ventricular Mass; LA: Left Atrial; VR: Right Ventricle; RVEDd: Right Ventricular End Diastolic Dimension EF : Ejection Fraction; FS: Fractional Shortening ; TAPSE : Tricuspid Annular Plane Systolic Excursion; MAPSE : Mitral Annular Plane Systolic Excursion ; DT : Deceleration Time; IVRT : Isovolumetric Relaxation Time

Table 6: Summary baseline characteristics in RA patients with diastolic dysfunction and normal function. 
Citation: Dodo-Siddo MN, Ndiaye MB, Bodian M, Sarr SA, Ndongo S, e tal. (2015) Research of Electrocardiographic and Echocardiographic Abnormalities in Rheumatoid Arthritis without Clinical Cardiovascular Events. J Arthritis 4: 154. doi:10.4172/2167-7921.1000154

Page 5 of 6

$41.50 \%$ and $3.80 \%$. The prevalence of diastolic dysfunction using conventional parameters of Doppler echocardiography of the mitral flow was $42.46 \%$. These results were similar to those in the literature $[28,29]$. The prevalence of impaired diastolic function in our study increases with age. It was higher in the age group of 51-60 where the prevalence was $35.48 \%$. This finding was reported by Sagie et al. [32], for which the alteration of the diastolic function is a function of patient age. Echocardiographic study by Gonzalez-Juanatey et al. [33] in patients with rheumatoid arthritis for many years but with no cardiovascular risk factors or cardiovascular disease authenticated, showed that there is still an increase in pulmonary blood pressure and diastolic dysfunction with a decrease of the relaxation ability of the left heart. In our series, pulmonary and tricuspid leakage was the most frequent. Tricuspid insufficiencies were present in 39 cases $(53.42 \%)$. The prevalence of mitral regurgitation was $16.43 \%$ and aortic $13.69 \%$. These results were different from those in the literature where mitral regurgitation was the most common [30] and most symptomatic aortic regurgitation and particularly poor prognosis [28]. Carlos et al. [28] found themselves a prevalence of the mitral and aortic insufficiency $12 \%$ while that of the tricuspid insufficiency was $3 \%$. The prevalence of pulmonary arterial hypertension was $21.05 \%$. There was a mild pulmonary hypertension. Dawson et al. [34], found a prevalence of $\mathrm{PAH} 31 \%$ and moderate isolated pulmonary hypertension (without heart or lung disease) was observed in $21 \%$ of patients.

\section{Conclusion}

Following this work we have found the existence of cardiac abnormalities in both electrically and echocardiographic in rheumatoid arthritis. Electrocardiogram and echocardiogram are a sensitive and reliable diagnostic aid for the detection of cardiac abnormalities in rheumatoid arthritis without clinical cardiovascular events.

\section{References}

1. Kvalvik AG, Jones MA, Symmons DP (2000) Mortality in a cohort of Norwegian patients with rheumatoid arthritis followed from 1977 to 1992. Scand J Rheumatol 29: 29-37.

2. Monson RR, Hall AP (1976) Mortality among arthritics. J Chronic Dis 29: 459467 .

3. Mutru O, Laakso M, Isomäki H, Koota K (1985) Ten year mortality and causes of death in patients with rheumatoid arthritis. Br Med J (Clin Res Ed) 290: 1797-1799.

4. Prior P, Symmons DP, Scott DL, Brown R, Hawkins CF (1984) Cause of death in rheumatoid arthritis. Br J Rheumatol 23: 92-99.

5. Danesh J, Whincup P, Walker M, Lennon L, Thomson A, et al. (2000) Low grade inflammation and coronary heart disease: prospective study and updated meta-analyses. BMJ 321: 199-204.

6. Solomon DH, Karlson EW, Rimm EB, Cannuscio CC, Mandl LA, et al. (2003) Cardiovascular morbidity and mortality in women diagnosed with rheumatoid arthritis. Circulation 107: 1303-1307.

7. Wolfe F, Freundlich B, Straus WL (2003) Increase in cardiovascular and cerebrovascular disease prevalence in rheumatoid arthritis. J Rheumatol 30 : $36-40$.

8. Solomon DH, Goodson NJ, Katz JN, Weinblatt ME, Avorn J, et al. (2006) Patterns of cardiovascular risk in rheumatoid arthritis. Ann Rheum Dis 65: 1608-1612.

9. Wolfe F, Michaud K (2004) Heart failure in rheumatoid arthritis: rates, predictors, and the effect of anti-tumor necrosis factor therapy. Am J Med 116: 305-311.

10. Crowson CS, Nicola PJ, Maradit-Kremers H, O'Fallon WM, Therneau TM, et al.(2005) How much of the increased incidence of heart failure in rheumatoid arthritis is attributable to traditional cardiovascular risk factors and ischemic heart disease? Arthritis Rheum 52: 3039-3044.

11. Vasan RS, Larson MG, Benjamin EJ, Evans JC, Reiss CK, et al. (1999)
Congestive heart failure in subjects with normal versus reduced left ventricular ejection fraction: prevalence and mortality in a population-based cohort. J Am Coll Cardiol 33: 1948-1955.

12. Arnett FC, Edworthy SM, Bloch DA (1988) Criteria for the classification of rheumatoid arthritis. Arthritis Rheum 31: 315-324.

13. http://agence-tst.ansm.sante.fr/html/ang/htm/1/1000c.htm

14. Sahn DJ, DeMaria A, Kisslo J, Weyman A (1978) Recommendations regarding quantitation in M-mode echocardiography: results of a survey of echocardiographic measurements. Circulation 58: 1072-1083.

15. Pham T, Gossec L, Constantin A, Pavy S, Bruckert E, et al. (2006) Cardiovascular risk and rheumatoid arthritis: clinical practice guidelines based on published evidence and expert opinion. Joint Bone Spine 73: 379-387.

16. Goulenok TM, Meune C, Gossec L, Dougados M, Kahan A, et al. (2010) Usefulness of routine electrocardiography in screening for cardiac involvement in spondylarthropathies and rheumatoid arthritis. Revue du Rhumatisme 77: 146-150.

17. Rexhepaj N, Bajraktari G, Berisha I, Beqiri A, Shatri F, et al. (2006) Left and right ventricular diastolic functions in patients with rheumatoid arthritis without clinically evident cardiovascular disease. Int J Clin Pract 60: 683-688.

18. Dryll A (1978) [Extraarticular manifestations of rheumatoid arthritis]. Acta Rhumatol Belg 2: 132-139.

19. Sany J, Drospy R, Daures JP (1998) Cross-sectional epidemiological survey of rheumatoid arthritis patients seen in private practice in France. Descriptive results (1629 cases). Rev Rhum. Engl Ed 65: 462-470.

20. Dieye A, Diallo S, Diatta M, Thiam A, Ndiaye R, et al. (1997) [Identification of HLA-DR alleles for susceptibility to rheumatoid polyarthritis in Senegal]. Dakar Med 42: 111-113.

21. Rudominer RL, Roman MJ, Devereux RB, Paget SA, Schwartz JE, et al. (2009) Independent association of rheumatoid arthritis with increased left ventricular mass but not with reduced ejection fraction. Arthritis Rheum 60: 22-29.

22. Redfield MM, Jacobsen SJ, Burnett JC Jr, Mahoney DW, Bailey KR, et al (2003) Burden of systolic and diastolic ventricular dysfunction in the community: appreciating the scope of the heart failure epidemic. JAMA 289: 194-202.

23. Wistowska M, Sypuła S, Kowalik I (1999) Echocardiographic findings and 24-h electrocardiographic Holter monitoring in patients with nodular and non-nodular rheumatoid arthritis. Rheumatol Int 18: 163-169.

24. Seferović PM, Ristić AD, Maksimović R, Simeunović DS, Ristić GG, et al. (2006) Cardiac arrhythmias and conduction disturbances in autoimmune rheumatic diseases. Rheumatology (Oxford) 45 Suppl 4: iv39-42.

25. Villecco AS, de Liberali E, Bianchi FB, Pisi E (1983) Antibodies to cardiac conducting tissue and abnormalities of cardiac conduction in rheumatoid arthritis. Clin Exp Immunol 53: 536-540.

26. Lutalo SK (1985) Chronic inflammatory rheumatic diseases in black Zimbabweans. Ann Rheum Dis 44: 121-125.

27. Barry F (1995) Cardiovascular manifestation of some systemic diseases a prospective study of 65 cases. Mem Cardiolol CES . Cheikh Anta Diop University in Dakar $\mathrm{N}^{\circ} 4$.

28. Carlos A, Roldan MD, Delong C, Qualls CR, Crawford MH (2007) Characterization of valvular heart disease in rheumatoid arthritis by transesophageal echocardiography andclinical correlates. Am J Cardiol 100 496-502.

29. Rudominer RL, Roman MJ, Devereux RB, Paget SA, Schwartz JE, et al Rheumatoid arthritis is independentlyassociated with increased left ventricular mass but not reduced ejection fraction. Arthritis Rheum 60: 22-29.

30. Redfield MM, Jacobsen SJ, Burnett JC, Mahoney DW, Bailey KR, et al. (2003) Burden of systolic and dias-tolic ventricular dysfunction in the community: appreciating the scope of the heart failure epidemic. JAMA 289:194-202.

31. Abdul Muizz AM, Mohd Shahrir MS, Sazliyana S, Oteh M, Shamsul AS, et al (2011) A cross-sectional study of diastolic dysfunction in rheumatoid arthritis and its association with disease activity. Int J Rheum Dis 14: 18-30.

32. Sagie A, Benjamin EJ, Galderisi M, Larson MG, Evans JC, et al. (1993) Reference values for Doppler indexes of left ventricular diastolic filling in the elderly. J Am Soc Echocardiogr 6: 570-576. 
Citation: Dodo-Siddo MN, Ndiaye MB, Bodian M, Sarr SA, Ndongo S, e tal. (2015) Research of Electrocardiographic and Echocardiographic Abnormalities in Rheumatoid Arthritis without Clinical Cardiovascular Events. J Arthritis 4: 154. doi:10.4172/2167-7921.1000154

Page 6 of 6

33. Gonzalez-Juanatey C, Testa A, Garcia-Castelo A, Garcia-Porrua C, Llorca $\mathrm{J}$, et al. (2004) Echocardiographic and Doppler findings in long-term treated rheumatoid arthritis patients without clinically evident cardiovascular disease. Semin Arthritis Rheum 33: 231-238.
34. Dawson JK, Goodson NG, Graham DR, Lynch MP (2000) Raised pulmonary artery pressures measured with Doppler echocardiography in rheumatoid arthritis patients. Rheumatology (Oxford) 39: 1320-1325 